\title{
PLENARY LECTURE: STATISTICS CAPACITY BUILDING IN A DEVELOPING COUNTRY - EXPERIENCES, OPPORTUNITIES AND CHALLENGES
}

\author{
Delia North \\ University of Natal, South Africa \\ northd@ukzn.ac.za
}

Statistics Capacity Building has traditionally been associated with building capacity in Official Statistics, i.e. the capability to collect, analyze and disseminate high quality data in a timely manner and analysing the data for effective functioning of government, the economy and society. Statistical Capacity Building in the 21st century encompasses the capability to deliver relevant statistics training for the needs in ALL areas of official statistics, as well as public and private sectors, academia, and research centres. This calls for education systems to deliver effective and updated statistics training across the spectrum, from basic data literacy to high level straining in the statistical sciences.

Challenges faced when building statistics capacity across the spectrum are well documented, however in developing countries, these challenges are similar, but often on a larger scale and more critical. The author will give an overview of lessons learnt and experiences in statistics capacity building initiatives in a developing country, at all levels in South Africa (school to $\mathrm{PhD}$ ), over a period of more than 25 years. 